\title{
Microcontroller-based Vessel Passenger Tracker using GSM System: An Aid for Search and Rescue Operations
}

\author{
Joel I. Miano ${ }^{* 1}$, Ernesto E. Empig ${ }^{2}$, Alexander R. Gaw ${ }^{3}$, Ofelia S. Mendoza ${ }^{4}$, Danilo C. Adlaon ${ }^{5}$ \\ Sheena B. Cañedo ${ }^{6}$, Roan Duval A. Dangcal ${ }^{7}$, Angelie S. Sumalpong ${ }^{8}$ \\ Computer Applications Department, College of Computer Studies \\ Mindanao State University-Iligan Institute of Technology \\ Iligan City, Lanao Del Norte, Philippines 9200
}

\begin{abstract}
The Maritime Transport industry in the Philippines has been growing through the years and has been a catalyst in the industrial development of the country. Although the maritime transport sector is one of the largest industries in the country, the safety devices and technology used are sluggish phase to change. The natural hazards and human error are main cause of maritime incidents, resulting to multiple casualties and missing persons every year of which this study seek to address the problem of safety in the maritime transport industry. The study aims to design and develop a system that will locate an overboard $^{1}$ passenger whenever a vessel is in distress. The Floating Overboard Accident Tracking System (FLOATS) was conceptualized by combining the Search Theory, Theory of Planned Behavior (TPB) and Disaster Preparedness, and the increasing availability of tracking device and monitoring technologies and the advancement of communication systems. The system consists of the Global Positioning System (GPS) for location data, Global System for Mobile (GSM) communications for the transmission and reception of emergency messages, Arduino-Nano microcontroller to handle the processing, the used of an inflatable life jacket with signal light and a rescue update display using an organic light emitting diode (OLED) for the search and rescue operations. Tests and surveys established the functionality, reliability, and acceptability of the system, which will greatly benefit maritime incident responders by securing vessel passengers from hazards and reducing the time allotted through speedy search and rescue operations.
\end{abstract}

Keywords-Global Positioning System (GPS); Global System for Mobile communications (GSM); Organic Light Emitting Diode (OLED); Arduino-Nano microcontroller; tracking system; life jacket; life jacket light

\section{INTRODUCTION}

Maritime transport is the foundation of globalization and is the center of cross-border networks of transport that aid supply chains and empower international trade [1]. The Philippines having composed of 7,641 islands makes its shipping transport industry a vital part of the economic growth and development. One may assume that because of the archipelagic nature of the Philippines, the maritime industry is traditionally anchored in its economy [2]. The country's archipelagic setting requires an efficient maritime transport infrastructure and systems of safety aids. According to a

\footnotetext{
* Corresponding Author
}

statistical report compiled by the Philippine Maritime Industry Authority (2016), there is an increasing rate of passenger traffic yearly [3]. In 2017, a total of 72,438,609 passenger traffic based on the total embarking and disembarking data was reported. Alongside the volume of passengers are risks regarding their safety. The Philippines being situated near the Pacific Ocean makes it one of the most vulnerable countries in the world to weather-related extreme events. The Philippines placed second among 171 countries ranked on their risk level to disasters the report added that the country lacks $80.03 \%$ of coping capacity to minimize the negative consequences of natural hazards and climate change through direct action and the resources available [4]. In 2012, there were 610 reported persons killed or missing (lives lost) worldwide [5]. In addition to this, it was also stated that human errors and fatigue were featured eminently in these accidents. Over the recent years, most casualties recorded from maritime incidents are from passenger or roll-on/roll-off (RO-RO) ships and general cargo ships. There are 185 average number of deaths due to maritime accidents in the country yearly [6]. In addition to this, a report released by MARINA in 2016 states that there were 707 Search and Rescue (SAR) missions, 211 casualties, and 216 persons missing related to maritime incidents on that year. Several memorandum and circulars were made to increase maritime safety and resilience to hazards [7]. An example of a provision under a memorandum is to upgrade the maritime safety infrastructures like the navigation aids, lighthouses, vessel monitoring services and systems, and other maritime ancillary services like the weather bureaus. Memorandums and circulars were also made to prevent maritime accidents. While strict regulations are implemented, the number of search and rescue operations as stated earlier in a report by MARINA in 2016 is relatively higher compared to 126 number of maritime search and rescue operations in 2015. Moreover, the increasing number of passenger traffic yearly, implies the need for an appropriate technology to counter the consequences of maritime incidents and promote disaster resilience particularly in the maritime transportation sector.

This study provides the design and development an appropriate technology to be used in times of maritime incidents. The technology is known as Floating Overboard Accident Tracking System (FLOATS) was integrated in a life jacket with an extend battery life span that sustains the 
tracking device ${ }^{1}$ through a solar panel therefore assuring a higher survivability, reducing the exposure of passengers involved in a maritime incident/accident or natural hazards and minimizing the time allocated in locating the strayed passengers aiding the authorities in search and rescue mission. Next section describes the system design model of FLOATS.

\section{SYSTEM DESIGN}

Fig. 1 shows design model of the FLOATS prototype components hardware and software developing the tracking device that is integrated to the life jacket, increasing the probability of success of a search and rescue operation through GSM, GPS, and OLED output.

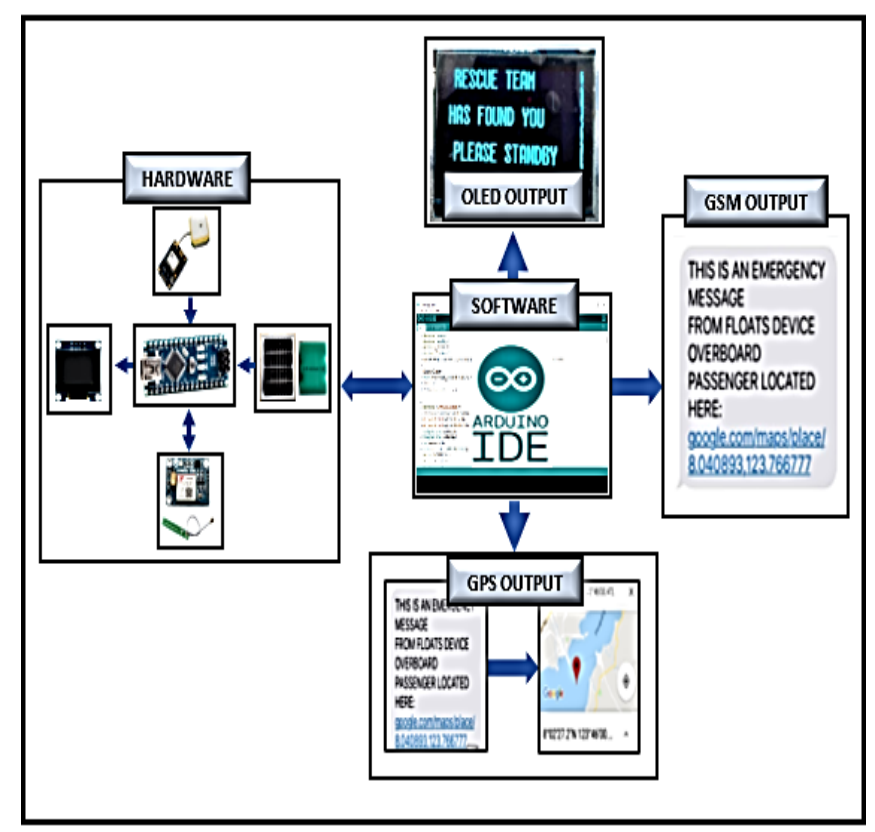

Fig. 1. Design Model of the FLOATS.

\section{A. Hardware}

1) Arduino Nano Boar ${ }^{2}$ - Arduino Nano is a small, complete, and breadboard-friendly board based on the ATmega328P. It has 22 Digital I/O pins and 8 Analog IN pins. The microcontroller board is used to handle the processes needed by the tracking device.

2) SIM800L GSM/GPRS Modul ${ }^{3}$ - SIM800L is a GSM Module that features a complete Quad-band GSM/GPRS solution in a LGA type. The module can transmit Voice, SMS, and data information with low power consumption. The tracking device's SMS interfacing is made possible by SIM800L.

3) Neo M8N GPS Module $-\mathrm{Neo} \mathrm{M} 8 \mathrm{~N}$ is a GPS Module used to retrieve location and time information from GPS satellites. The Neo M8N GPS Module is a significant component of the tracking device that receives location information of the overboard passenger.

\footnotetext{
https://www.merriam-webster.com

${ }^{2}$ https://store.arduino.cc/usa/arduino-nano

${ }^{3}$ https://lastminuteengineers.com/sim8001-gsm-module-arduino-tutorial/

${ }^{4}$ https://www.u-blox.com/en/product/neo-m8-series

${ }^{5}$ https://www.thefreedictionary.com/OLED
}

4) OLED Display ${ }^{5}$ - Organic Light Emitting Diode (OLED) Display is an efficient and thinner display that can light up individual pixels when necessary and to different degrees. The maximum resolution of the OLED Display is 128x64. The OLED display shows the rescue updates sent by the search and rescue authorities.

5) $\mathrm{Ni}-\mathrm{MH}$ Battery ${ }^{6}$ - the battery used in the tracking device has a voltage of $7.2 \mathrm{~V}$ with a capacity of $2200 \mathrm{mAh}$.

6) Solar $\mathrm{Panel}^{7}$ - used in addition to mains-supply chargers for energy saving during the daytime with a maximum voltage of $17.5 \mathrm{~V}$, current of $0.57 \mathrm{~A}$ and maximum power of $10 \mathrm{~W}$.

\section{B. Software}

Arduino Integrated Development Environment ${ }^{8}$ (IDE) Arduino IDE is an open-source software program that allows user to write and upload code within a real-time work environment. The IDE had been instrumental in writing, compiling, and uploading codes to the Arduino Board. Writing the individual codes for each module and integrating all of them were vital in developing the firmware for the tracking device.

\section{METHODOLOGY}

Fig. 2 illustrates the comprehensive flow of the whole research process to guide the researchers in creating a prototype with an appropriate technology namely the Floating Overboard Accident Tracking System (FLOATS).

\section{A. Analysis and Data Gathering}

In this stage, the researchers started gathering data and relevant information, conducting preliminary investigation and interviews. Gathering and supporting facts about the existing problem to be able to design and develop the FLOATS. The researchers investigated first the scale of the problem in the Philippines. Having read articles and releases by the World Risk Report of the United Nations University Institute for Environment and Human Security, the researchers found out that the Philippines placed second among the 171 countries ranked on their risk level to disasters. The Philippine lacks eighty-percent $80 \%$ of coping capacity to minimize the negative consequences. With the increasing number of passenger traffic in the maritime transport industry of the country, the researchers saw the importance of safety in this particular sector. Secondary data from the Philippine Maritime Industry Authority (MARINA) and the Philippine Coast Guard (PCG) further supports the claim that there is an increasing number of search and rescue operations regarding maritime incidents in the Philippines. Researchers conducted a survey at the City Disaster Risk Reduction Management Office and Philippine Coast Guard Iligan Station concerning the existing tracking devices [12]. Based on the interviews conducted with the authorities, the researchers found out that there were no tracking devices used to locate or track overboard passengers when doing search and rescue operations.

\footnotetext{
${ }^{6}$ https://en.wikipedia.org/wiki/Nickel\%E2\%80\%93metal_hydride_battery

${ }^{7} \mathrm{https}: / /$ www.conserve-energy-future.com

${ }^{8}$ https://en.wikipedia.org/wiki/Arduino_IDE
} 


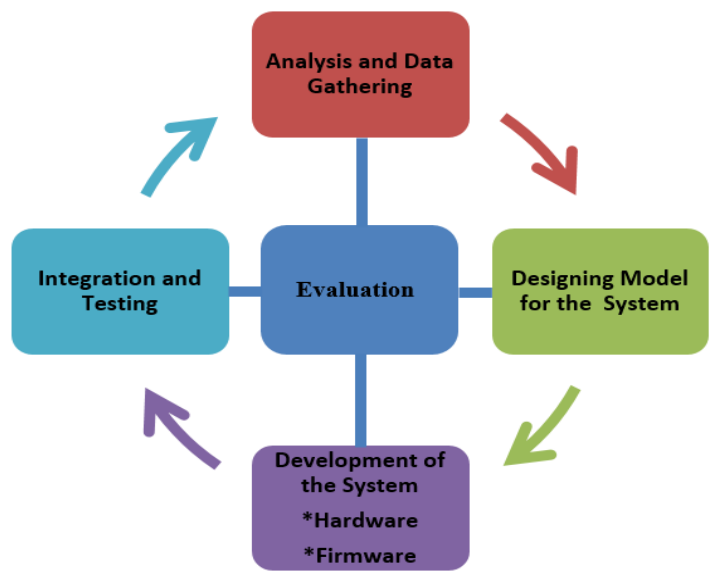

Fig. 2. Research Methodology.

To understand the underlying technical and conceptual aspects of a search and rescue operation, the researchers came across with the Search Theory [8]. As the foundation of modern search and rescue operations, Search Theory became a pillar of this study. Sweep width, an indicator whether search conditions are ideal or not is heavily considered in the study. Sweep width is a key factor in determining the Probability of Success (POS) of a search and rescue operation.

\section{B. Designing Model for the System}

Developing the FLOATS, the researchers designed a model (Fig. 1) for the system with the following brief operation procedure:

a) When the life vest is submerged in the water, the life vest will automatically inflate. The victim must press the button to activate the device. An initialized message will be display on the OLED indicating that the device is activated. After 30 seconds, it will then send a message to the designated receiver's number via SMS (short message service).

b) The receiver will receive a message containing an overboard passenger's location converted to hyperlink including latitude and longitude coordinates that will point to the victim's exact location.

c) When the hyperlink is tapped, it will take the receiver to the web mapping service Google Maps. Then the device sends the first location message in 30 seconds, and the succeeding location messages are sent every one minute.

d) The rescuer can also send pre-configured messages to the victim, namely, 'RCD', 'OTW'; 'FND' as an assurance to the victim, the pre-configured message will be displayed to the OLED in Fig. 3. The device's reliability depends on the signal strength of the chosen network of mobile communications.

\section{Development of the System}

From the gathered data the researchers came up with a suitable design for the hardware that is fit for the maritime environment. The use of a Global Positioning System (GPS) device in the system corresponds to the Search Theory where the Probability of Detection (POD) is important especially during the planning phase of a search and rescue mission. The importance of POD also propelled the users to use the Global System for Mobile communication (GSM) as the transmission and reception means of the tracking system [10]. The use of a highly-reflective color of life jacket was also considered in the development of the device. Search objects can be easily detected when they contrast their background. In case of a night time incident, the use of lifejacket light is employed. An OLED display in Fig. 4 was also considered for the search and rescue updates.

The gathered data and the application of theories, models and frameworks were analyzed. The hardware needed such as the components and modules used were gathered. Each component was tested Fig. 5 integrating them all in a single circuit.

A circuit design was developed and all hardware components were integrated into a single circuit. Multiple simulations were executed on the tracking device to test if the system operates on its defined operation. One of the largest obstacles the researchers faced during the hardware development stage is the integration of the GSM and GPS modules. By troubleshooting and through continued tests, all the hardware components were successfully integrated.

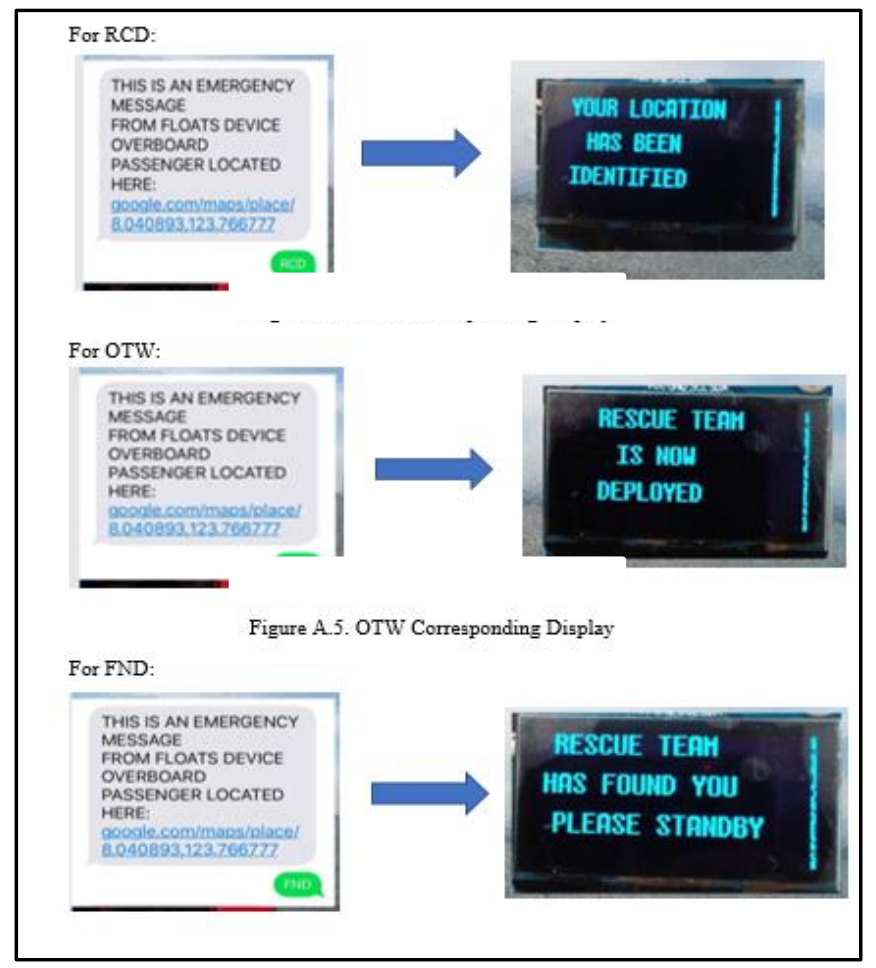

Fig. 3. Web Mapping Service Google Maps.

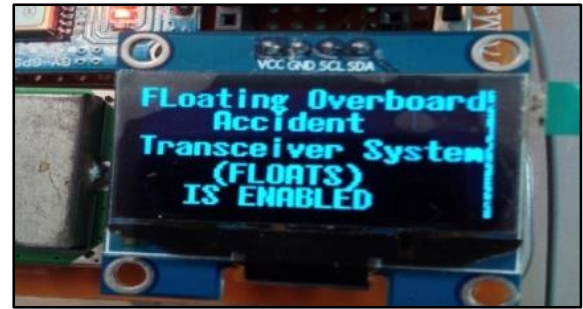

Fig. 4. OLED Display. 


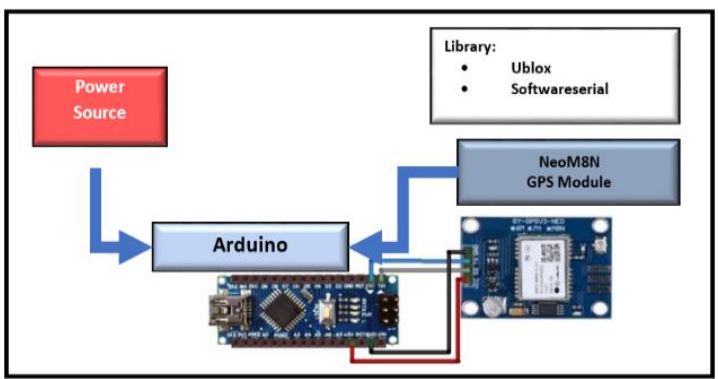

(A)



(B)

Fig. 5. (A). Arduino Board and GPS Module Block Diagram, (B). Arduino Board and GSM Module Block Diagram.

In the same manner as the hardware development of the system, gathering data and analyzing it is the foundation of all the processes. To make sure all components are functional, before doing so, the researchers tested the components individually. This includes GSM module, GPS module, OLED, solar panel and the battery [11]. All these components were then connected to the microcontroller board known as Arduino Nano. Before a final code was written, individual codes were developed according to each component of the tracking device. The codes are written, compiled, and uploaded to the Arduino Nano board through the Arduino IDE. The loaded program of each component was uploaded and simulated. At times, the researchers would notice that the device was not working based on its defined function. Each respective code would then be debugged to find and resolve code problems. After testing each code, a final code was written derived from each component's code. The researchers integrated the final code to the system, combining the components as a whole.

\section{Integration and Testing of the System}

In this phase, the researchers tested the hardware and firmware used in making the device and integrated it as a whole. Troubleshooting, debugging and real-time tests are employed in this phase. Each major component of the Floating Overboard Accident Tracking System (FLOATS) was tested with their respective codes. Troubleshooting and debugging were important processes in achieving the correct operation of the system. Lastly, all of the major components were eventually integrated. The evaluation stage is a multi-cross stage throughout the whole study. The hardware and firmware used for example are evaluated if its necessity is high through previously discussed theories, models and international standards. However, the evaluation stage is also where the final prototype is assessed and recorded based on its functionality, reliability and acceptability.

\section{SYSTEM RESULTS AND DISCUSSION}

The importance of Search Theory, the Theory of Planed Behavior and Disaster Preparedness makes the researcher's concerned with the appropriate technology aspect of the study, on such theories helped the researchers how to counter the problem in a conceptual manner. Sweep width, which is the main indicator of Search Theory has been helpful to the researchers by considering its factors. The researchers applied the factors to practical specifications of an object to be used during a search and rescue operation. Table I points some concepts of a sweep width and the actual specification of an object used in the FLOATS.

In this study, the device integrates both floatation and tracking attached to the overboard vessel passenger. In order to cater the different weight classification of passengers, the researchers chose a life jacket that can handle a passenger with weight not exceeding 150 kilograms. A person is perceived as a large object from afar through the help of the automatic inflation feature of the life jacket. Thus, increasing the visual detection of the overboard vessel passenger. In addition to this, the color of the life jacket also improved the probability of detection of a passenger as it contrasts the background of the search area which is the blue sea/ocean water. On the other hand, a night time search and rescue operation requires a search object to have illumination. Therefore, the researchers attached an automatic light to the life jacket. Meanwhile, the reflectivity factor was provided by the Safety of Life at Sea (SOLAS)-approved reflective tape of the life jacket. Since the system used electronic means to locate an overboard passenger, sweep width heavily considers the signal strength which in the study is specified as the signal strength of the mobile communications network used.

\section{TABLE. I. FLOATS ACTUAL SPECIFICATION}

\begin{tabular}{|l|l|}
\hline Parts & Device Specification \\
\hline \multirow{3}{*}{ Life Jacket } & $\begin{array}{l}\text { a. Type - 150 kg maximum weight } \\
\text { b. Size - Inflatable } \\
\text { c. Color - Bright Yellow Orange } \\
\text { d. Illumination - Automatic Light } \\
\text { e. Reflectivity - SOLAS (Safety of Life at Sea Treaty) Reflective Strap }\end{array}$ \\
\hline \multirow{3}{*}{ Tracking System } & $\begin{array}{l}\text { a. Signal - GSM (Global System for Mobile Communications) } \\
\text { b. Location Tracking- GPS (Global Positioning System) } \\
\text { c. Display - OLED (Organic Light Emitting Diode) Screen Display }\end{array}$ \\
\hline Supply & $\begin{array}{l}\text { a. Type - Lithium Ion Battery } \\
\text { b. Solar Panel Type - Mini Polycrystalline Solar Panel }\end{array}$ \\
\hline
\end{tabular}


The researchers also considered the behavioral concepts of a passenger bound to be exposed to hazards caused by a maritime incident. The Theory of Planned Behavior stated that attitude, social pressure, and control are the factors that determine an intention to engage in a behavior at a specific time and place [9]. As to the problem concerning this study, the researchers considered the place where a person engages a specific behavior which is in a maritime incident setting. When the FLOATS is implemented during a maritime incident, the attitude of a vessel passenger that is bound to be distressed might change from a state of apprehension to a state of assurance. Social pressure might inflict panic among vessel passengers. However, the system might reduce the level of it.

The study emphasized the development and integration of the tracking device with solar panel to the life jacket. After the components were individually tested and integrated to form the tracking device, the problem on whether the tracking device was possible to be fully-integrated to the life jacket surfaced. Fig. 6 shows the final integration of the prototype.

Since the researchers have used prototyping modules to make the tracking device possible, it was difficult to fully integrate the tracking device to the life jacket. The researchers view the size of these prototyping modules as the main contributory factor to the obstacle of the integration. In addition to this, altering the original design of the life jacket might dispute its original function and damage it in the long run. To deal with this obstacle, the researchers used a carabiner and attached the tracking device to the strap of the life jacket.

The functionality of the FLOATS is evaluated by recording the results throughout the whole system operation specifically the response time of the device. Table II exhibits the response time of the tracking device SMS receive from each trial.

In the overall response time test result, five trials were executed by the researchers. The time was tracked using a smart phone's stopwatch. Through the results shown on the table, each operation time (in seconds) is averaged. It would take an average of 4.698 seconds for the initialization message to be displayed. On the other hand, the SMS sent display would take an average of 9.798 seconds. From the passenger's location, it would take an average of 8.288 seconds to reach the rescuer from the time the SMS sent display is flashed on the tracking device. And, the rescue update sent by a rescuer to the passenger in average would take 3.98 seconds to be displayed on the OLED of the tracking device. The results imply that by using the FLOATS tracking device, in a matter of seconds whenever vessel passengers are forced overboard, rescuers can already receive location data and start tracking the passengers.

This would significantly decrease the time allotted for searches and uplift the feeling of assurance for the vessel passengers. The researchers conducted a real-time test of the tracking device on the surface waters of the Panguil Bay. Two members of the research team were on the field to test the tracking device. Meanwhile, the third member was assigned to gather the location data sent by the tracking device. The third member stays in the Disaster Risk Reduction Management Office (DRRMO) of the Municipality of Tubod, Lanao del Norte. The two members on the field were accompanied by two rescuers from Tubod-DRRMO to guarantee the safety of the testing. In every location point, the boat used by the research team will turn to a halt until 5 location data are obtained. The trial lasted for two hours. The areas included in the testing of the tracking device include the municipalities of Tubod and Baroy in the province of Lanao del Norte and Barangay Silanga of Tangub City. Table III exhibits all the location points gathered during the testing of the tracking device.

Trial 1 of the first location had the location result of 8.078998 and 123.795753. The first set of numbers, specifically 8.078998 , indicates the latitude coordinate of the location data. The latter indicates the longitude coordinate. Both are vital for its plotting on a web-based mapping service. By using a web-based mapping service called Google Maps and its counterpart Google Earth, the researchers plotted all the location data resulting to the image (Fig. 7).

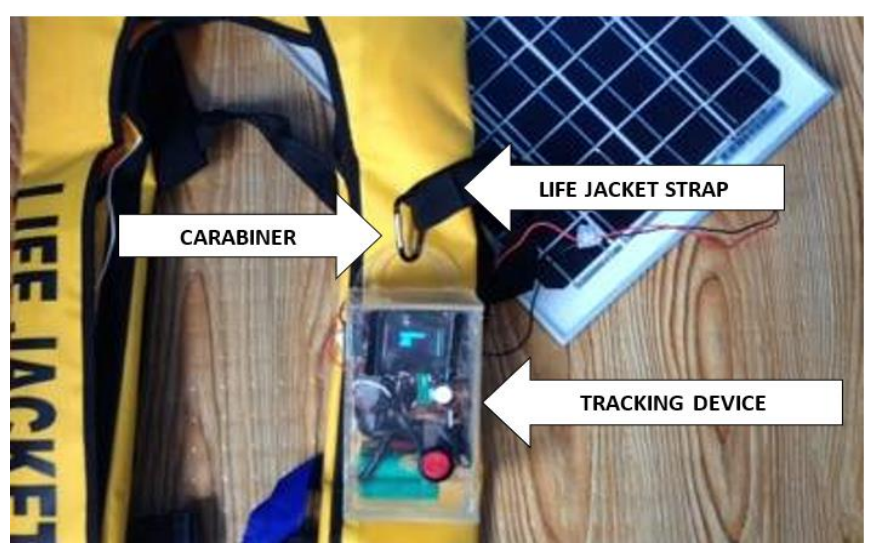

Fig. 6. Integration of the Prototype.

TABLE. II. FUNCTIONALITY OF THE FLOATS

\begin{tabular}{|l|l|l|l|l|l|}
\hline No. of Trials & Initialization Display (sec) & SMS Sent Display & \multicolumn{2}{l|}{$\begin{array}{l}\text { Location Message } \\
\text { Receive }(\boldsymbol{\vee}, \mathbf{x})(\text { Sec) }\end{array}$} & Rescue Update Display (sec) \\
\hline Trial 1 & 4.82 & 9.58 & $\checkmark$ & 8.57 & 5.41 \\
\hline Trial 2 & 3.44 & 9.74 & $\checkmark$ & 7.76 & 3.22 \\
\hline Trial 3 & 4.90 & 10.09 & $\checkmark$ & 8.38 & 4.40 \\
\hline Trial 4 & 4.81 & 9.82 & $\checkmark$ & 8.68 & 3.30 \\
\hline Trial 5 & 5.52 & 9.76 & $\checkmark$ & 8.05 & 3.57 \\
\hline Average & 4.698 & 9.798 & ok & 8.288 & 3.98 \\
\hline
\end{tabular}


TABLE. III. FLOATS TESTING OF THE FLOATS TRACKING DEVICE

\begin{tabular}{|l|l|l|l|l|l|}
\hline \multirow{2}{*}{$\begin{array}{l}\text { Location Area } \\
\text { (Latitude, Longitude) }\end{array}$} & \multicolumn{2}{|l|}{ No. of Trials } & Trial 2 & Trial 3 & Trial 4 \\
\cline { 2 - 6 } & Trial 1 & & & Trial 5 \\
\hline $\begin{array}{l}\text { Tangueguiron, Tubod } \\
\text { Somewhere } \\
\text { Alim Shrine }) \\
8.080128,123.796287\end{array}$ & $8.078998,123.796287$ & $8.078836,123.795768$ & $8.078648,123.795799$ & $8.078311,123.795799$ & $8.078311,123.795799$ \\
\hline $\begin{array}{l}\text { Tubod Port } \\
8.05708,123.782714\end{array}$ & $8.056834,123.782714$ & $8.055989,123.782196$ & $8.055922,123.782096$ & $8.055735,123.781997$ & $8.055574,123.781898$ \\
\hline $\begin{array}{l}\text { Sagadan, Tubod } \\
\text { (MCC HOTEL) } \\
8.048721,123.775749\end{array}$ & $8.047289,123.77414$ & $8.045537,123.772735$ & $8.04344,123.772544$ & $8.045242,123.772415$ & $8.044876,123.772117$ \\
\hline $\begin{array}{l}\text { Baroy, Tubod } \\
\text { (Seaside Cuzina Bar) } \\
8.033973,123.758476\end{array}$ & $8.033945,123.75846$ & $8.033936,123.758201$ & $8.033894,123.758102$ & $8.033854,123.757987$ & $8.033809,123.757843$ \\
\hline $\begin{array}{l}\text { Silanga, Tangub City } \\
\text { (Silanga Port) } \\
8.064160,123.77534\end{array}$ & $8.064497,123.775749$ & $8.064688,123.776054$ & $8.064755,123.776222$ & $8.064462,123.776809$ & $8.064395,123.777114$ \\
\hline
\end{tabular}

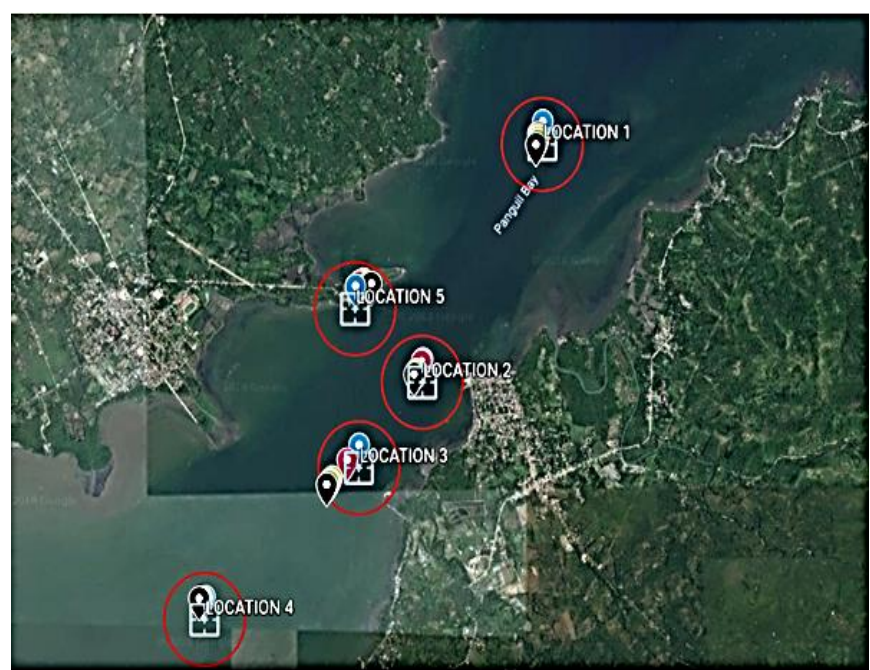

Fig. 7. Google Maps Location Data Result.

Table IV shows the distance between other four trials ( 2 to 5) from the reference location to trial 1, using the distance ruler attributes in the Google map application the outcome presented in Fig. 8 location points gathered during the testing of the tracking device.

Fig. 9 shows the actual test floats tracking device receive SMS from the rescuer's smart phone enable the passenger to be located via hyertxt link of google maps from the tracking device.

TABLE. IV. Distance BETWEEN LOCATION FROM TRIAL 1 FLOATS TESTING

\begin{tabular}{|l|l|}
\hline \multicolumn{2}{|l|}{ Distance Between Location From Trial 1 (meters) } \\
\hline Distance A (Trial 1 - Trial 2) & $16 \mathrm{~m}$ \\
\hline Distance B (Trial 1 - Trial 3) & $27 \mathrm{~m}$ \\
\hline Distance C (Trial 1 - Trial 4) & $41 \mathrm{~m}$ \\
\hline Distance B (Trial 1 - Trial 5) & $57 \mathrm{~m}$ \\
\hline
\end{tabular}

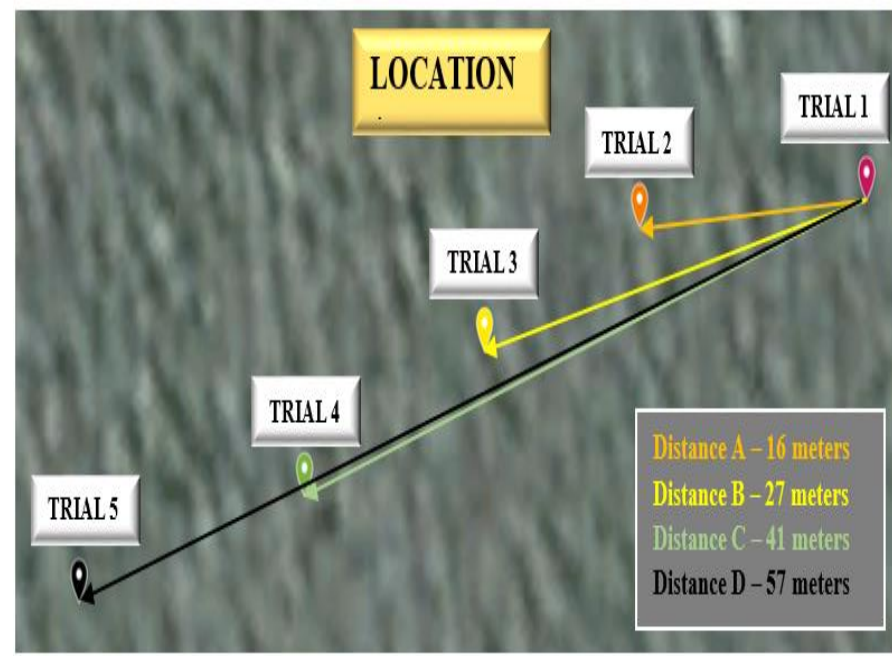

Fig. 8. Location Data Result.

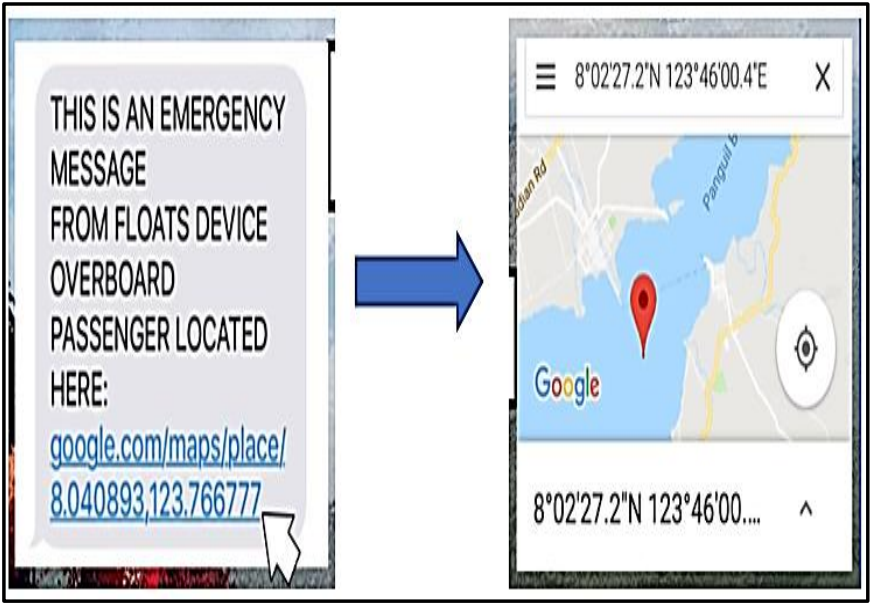

Fig. 9. Actual Test FLOATS Tracking Device. 
TABLE. V. ACCEPTABILITY OF THE FLOATS TRACKING DEVICE

\begin{tabular}{|c|c|c|c|c|c|}
\hline Statement & $\begin{array}{l}\text { Strongly } \\
\text { Disagree }\end{array}$ & Disagree & Neutral & Agree & $\begin{array}{l}\text { Strongly } \\
\text { Agree }\end{array}$ \\
\hline 1. The life jacket is user-friendly. & & & & 3 & 15 \\
\hline $\begin{array}{l}\text { 2. The device does not interfere with } \\
\text { simple movements while the } \\
\text { user is in the water. }\end{array}$ & & & 2 & 3 & 10 \\
\hline $\begin{array}{l}\text { 3. The placement of the device is } \\
\text { comfortable while the user is still in the } \\
\text { water. }\end{array}$ & & & & 9 & 9 \\
\hline 4. The OLED display is readable & & & 1 & 4 & 13 \\
\hline $\begin{array}{l}\text { 5. The rescue details displayed give the user } \\
\text { confidence towards the rescuers. }\end{array}$ & & & 1 & 6 & 11 \\
\hline $\begin{array}{l}\text { 6. The device is helpful in locating an } \\
\text { overboard passenger }\end{array}$ & & & 2 & 6 & 10 \\
\hline $\begin{array}{l}\text { 7. The device will be helpful in decreasing } \\
\text { the number of missing passengers in a case } \\
\text { of maritime accident. }\end{array}$ & & & & 2 & 16 \\
\hline $\begin{array}{l}\text { 8. The device can be made as an 'essential } \\
\text { item' to daily water transport. }\end{array}$ & & & 1 & 7 & 10 \\
\hline $\begin{array}{l}\text { 9. The application of the device is not only } \\
\text { limited to vessel passengers. }\end{array}$ & & & & 7 & 11 \\
\hline $\begin{array}{l}\text { 10. Would you recommend this system to } \\
\text { be applied in the transportation industry of } \\
\text { the country? }\end{array}$ & & & 1 & 4 & 13 \\
\hline TOTAL & & & 8 & 54 & 118 \\
\hline Percentage & & & $3.73 \%$ & $30.34 \%$ & $66.29 \%$ \\
\hline
\end{tabular}

Shown in Table $\mathrm{V}$ is the survey questionnaire result regarding how the general public accepted the device.

In general (Fig. 10), majority of respondents, specifically $66.29 \%$ strongly agreed to most of the statements in the survey questionnaire. $30.34 \%$ merely agreed and $3.37 \%$ were tallied for neutral ratings. Moreover, the most agreed statement in the survey questionnaire is statement number seven, emphasizing the level of confidence the respondents have for the system's potential in minimizing the number of missing persons caused by a maritime incident. The results regarding the survey questionnaire implies that there is a high acceptability of the Floating Overboard Accident Tracking System.

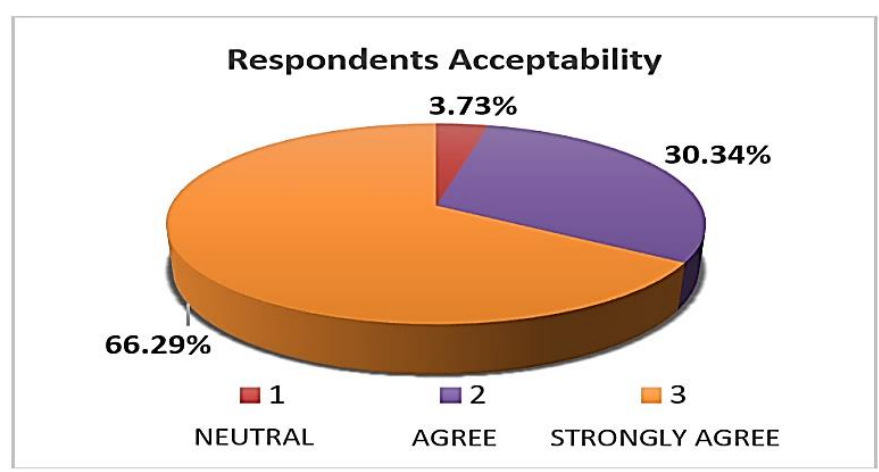

Fig. 10. Respondents Acceptabilty Graph of FLOATS Tracking Device.
Natural hazards and human error are inevitable factors in the maritime transportation sector of the country. With the increase of passenger traffic yearly, protecting the human resource of the country should be a priority, specifically those who frequently use maritime transport because of economic and efficiency factors. To counter the risks of passenger's exposure to the hazards caused by a maritime incident, the researchers designed and developed the Floating Overboard Accident Tracking System (FLOATS): (a) The concept of making one-sided searches into two-sided searches by means of designing and developing a system that the passengers and rescuers can use simultaneously was made possible. (b) The Theory of Planned Behavior on the other hand gave the researchers idea on how safety devices and tracking devices are perceived by passengers in an actual maritime incidence. (c) The researcher's successfully designed and developed a system that was intended to locate overboard passengers in a maritime incident. (d) Using GSM module, the tracking device can send its first location message to a rescuer's mobile phone in an average time of 8.28 seconds. (e) The rescuer's search and rescue update response can be sent and displayed to the passenger tracking device's OLED display in an average of 3.98 seconds.

This confirmed the system's high response level. Thus, it was designed and developed successfully. The reliability factor on the other hand was indicated by the choice of a 
mobile network and its signal strength. The acceptability part of survey results show that the tracking system was met with high acceptance with $66.29 \%$ strongly agree the use of FLOATS.

This study effectively develops a tracking device with the appropriate technology that can be used by passengers during vessel capsizing at sea. The researchers emphasize the importance of safety in the maritime transportation industry and by applying the system to the current situation of the industry, the risks regarding passenger safety while at sea can be reduced.

\section{ACKNOWLEDGMENT}

This Research work is done by the undergraduate student of Bachelor of Science in Electronics and Communication Technology with the advice and support of the faculty of Computer Application Department.

\section{REFERENCES}

[1] United Nations Conference on Trade and Development (UNCTAD) (2016). Review of Maritime Transport: Fostering the transparency of maritime markets and analyzing relevant developments. Retrieved May 23, 2018, from https://unctad.org

[2] Lara Richter (2016). The Impact of the Maritime Industry on the Philippine Economy. German-Philippine Chamber of Commerce and Industry, Inc. Makati City 1234, Philippines. Avilable in https://philippinen.ahk.de/fileadmin/AHK_Philippinen/Publications/Mar itime_Industry_in_the_Philippines_GPCCI_2016_.pdf

[3] Maritime Industry Authority (MARINA) (August 2018). Annual Report on Basic Maritime Statistics: the available maritime and maritimerelated statistical information from the year 2012 up to the year 2016. Retrieved October 8, 2018, from http://marina.gov.ph
[4] United Nations University Institute for Environment and Human Security (UNU-EHS) (2014). The World Risk Report 2014. Available: online. https://i.unu.edu.

[5] Stipe Galic, Zvonimir Lusic, and Ivica Skoko (2014, April 28-29). 6th International Maritime Science Conference (IMSC): The Role and Importance of Safety in Maritime Transportation. Availble in https://bib.irb.hr

[6] Martinez RE, Go JJ and Guevarra J (2016). Epidemiology of drowning deaths in the Philippines, 1980 to 2011. Western Pac Surveill Response J. 2016 Nov 8;7(4). doi:10.5365/wpsar.2016.7.2.005. Available: online. http://ojs.wpro.who.int

[7] Orlando S. Dimailig, Jae-Yong Jeong, and Chol-Seung Kim (June 2011). Marine Transportation in the Philippines: The Maritime Accidents and their Causes. Available: online. https://www.researchgate.net

[8] U.S. Coast Guard Research and Development Center. Review in Search Theory: Advances and Applications to Search and Rescue Decision Support. Report No. CG-D-12-01, Washington ,DC. National Technical Information Service, SpringField, VA 22161. Available: online. https://apps.dtic.mil/dtic/tr/fulltext/u2/a397065.pdf

[9] Icek Ajzen (1991). The theory of planned behavior. Organizational behavior and human decision processes 50 (2), 179-211

[10] Arwa Masoud Hamza El-Nasri (June 2011). Design and Implementations of GPS Mobile Tracking System: Overall Tracking Centre Design. Retrieved December 12, 2018, from http://khartoumspace.uofk.edu

[11] Ralph H. Balingasa , Maria Tricia Camille R. Bilog , Jonnelle Klenn D. Castillo, Jerome M. Perez, Agnes F. Terrible, \& Rionel B. Caldo. Distress Signal Tracker Using GPS and SMS Technology: A Prototype. Retrieved December 12, 2018, from http://lpulaguna.edu.ph

[12] Ernesto Empig, Joel Miano, Harreez Villaruz, Nieva Mapula, et.al, 2015, Development of Digital Human Body Tracker Alarm System Using GPS and Transceiver for Catastrophic Events Rescue Operation (DHBT AS), 8th AUN/SEED-Net Regional Conference on Electrical and Electronics Engineering. https://uyr.uy.edu.mm/handle/ $123456789 / 371$. 